07

\title{
Исследование строения поверхности разрушения гетерогенного тела (кварцевого песчаника)
}

\author{
() В.И. Веттегрень ${ }^{1}$, Р.И. Мамалимов ${ }^{1}$, В.Б. Кулик ${ }^{1}$, А.В. Патонин ${ }^{2}$, А.В. Пономарев ${ }^{3}$, \\ Г.А. Соболев ${ }^{3}$, И.П. Щербаков ${ }^{1}$ \\ ${ }^{1}$ Физико-технический институт им. А.Ф. Иоффре РАН, \\ Санкт-Петербург, Россия \\ ${ }^{2}$ Геофизическая обсерватория „Борок“ - фрилиал Института фризики Земли им. О.Ю. Шмидта РАН, \\ Борок, Россия \\ ${ }^{3}$ Институт фоизики Земли им. О.Ю. Шмидта РАН, \\ Москва, Россия \\ E-mail: Victor.Vettegren@mail.ioffe.ru
}

(Поступила в Редакцию 8 декабря 2016 г.)

\begin{abstract}
Методами инфракрасной, фотолюминесцентной и рамановской спектроскопии исследовано строение поверхностных слоев кварцевого песчаника толщиной $\sim 1 \mu \mathrm{m}$ до и после разрушения под действием сжимающего напряжения. До разрушения этот слой содержал зерна кварца, цементированные монтмориллонитом и каолинитом. Зерна покрыты тонким слоем воды и содержат дефекты строения кристаллической решетки: $\mathrm{Si}-\mathrm{O}^{-}$, самозахваченные экситоны, соединения $\mathrm{AlOH}, \mathrm{LiOH}$, центры $\left[\mathrm{AlO}_{4}\right]^{-}$и др. Разрушенная поверхность содержит отдельные зерна кварца размером $\sim 2 \mu \mathrm{m}$. Концентрация дефектов строения в них понижена. Предполагается, что дефекты уменьшают прочность зерен кварца и они разрушаются в первую очередь.
\end{abstract}

Работа выполнена при финансовой поддержке РФФИ (грант № 16-05-00137).

DOI: 10.21883/FTT.2017.07.44594.436

\section{1. Введение}

Согласно современным представлениям, в основе возникновения землетрясений лежит неустойчивость скольжения земных плит [1-4]. При трении поверхности контактирующих пород часто сглаживаются, и образуются так называемые зеркала скольжения. Прямые исследования строения зеркал скольжения на поверхности гетерогенных твердых тел - горных пород (песчаника ПВ 364, порфирита и доломита) - были проведены в работах [5-7]. Было обнаружено, что они состоят из нанокристаллов минералов с низким коэффициентом трения. Затем было проведено исследование поверхностного слоя толщиной $30 \mathrm{~nm}$, образовавшегося на поверхности песчаника ПВ 364 после трения в лабораторных условиях [8]. Оказалось, что этот слой как природное зеркало состоит из нанокристаллов минерала с низким коэффициентом трения - монтмориллонита. Таким образом, во всех упомянутых случаях разрушение кристаллических решеток твердых тел привело к изменению химического строения поверхности: на ней образовался слой вещества с низким коэффициентом трения.

Это обстоятельство и послужило стимулом для появления настоящей работы. Для исследования был взят кварцевый песчаник - гетерогенное тело, содержащее в основном кристаллы кварца и полевого шпата с линейными размерами $\sim 2 \mu \mathrm{m}$, цементированные низкопрочными осадочными породами. Предполагалось, что при трении изменение химического строения поверхности песчаника будет минимальным: будут разрушаться только цементирующие породы, а поверхностный слой после трения будет содержать только порошок из кристаллов кварца и полевого шпата.

\section{2. Методика эксперимента}

Исследованный образец представлял собой цилиндр диаметром $30 \mathrm{~mm}$ и высотой $60 \mathrm{~mm}$. Для его деформации построена камера высокого давления, представляющая собой толстостенный стакан, внутрь которого помещается образец. Камера имеет подвижный поршень, который передает усилие, создаваемое прессом, вдоль оси цилиндра. Гидростатическое давление $30 \mathrm{MPa}$ внутри камеры создается насосной станцией путем закачки масла. Предполагалось, что такой способ нагружения сжатие в одном направлении и одинаковое давление в двух других - моделирует условия разрушения горных пород в земной коре.

Камера помещалась в гидравлический двухкамерный пресс INOVA, имеющий систему сервоконтроля [9]. C помощью программы управления задавалась временна́я зависимость смещения положения поршня пресса — скачки по $43.92 \mu \mathrm{m}$ через $400 \mathrm{~s}$. Когда величина сжимающего напряжения достигла $\sim 165 \mathrm{MPa}$, образец раскололся на две части под углом $\sim 35-40^{\circ}$ к оси цилиндра.

Для исследования строения поверхностей образца были использованы методы инфракрасной (IR), фотолюминесцентной (PL) и рамановской спектроскопии.

Чтобы получить спектры PL, была построена лабораторная установка. В ней луч ультрафиолетового светодиода UVTOP280TO39HS (длина волны излучения $285 \mathrm{~nm}$ ) 
падал на поверхность образца. Излучение, возникающее под действием луча светодиода, кварцевым световодом направлялось в спектрометр AvaSpec-ULSi2048L-USB2 OЕM. Диаметр луча светодиода, падающего на исследуемую поверхность, составлял $2 \mathrm{~mm}$, что на порядок меньше размеров площади торца и поверхности разрушения цилиндра. Поэтому измерения методом PL проводились в трех разных местах. Полученные данные усреднялись. На величину интенсивности полос в спектре PL сильно влияет рассеяние на шероховатой поверхности образца. Поэтому интенсивность излучения светодиода подбиралась такой, чтобы величина рассеянного излучения во всех трех местах была одинаковой.

IR-спектры отражения регистрировались на Фурьеспектрометре IR-21 „Prestige“, снабженном приставкой SRM-8000A. Диаметр луча излучения, падающего на исследуемую поверхность, составлял $20 \mathrm{~mm}$. Это означает, что методом IR-спектроскопии были получены сведения о содержании минералов в поверхностном слое породы, усредненные по площади, близкой к площадям торцов цилиндра и поверхности разрушения.

Рамановские спектры от поверхности образца записывались на спектрометре Ramalog-5 в режиме счета фотонов. Спектры возбуждались аргоновым лазером $\mathrm{Ar}^{++} 16508$ (Spectra Physics), линия $514.5 \mathrm{~nm}$. На поверхность образца, установленного на предметном столике, направлялся луч лазера, сфокусированный в пятно диаметром $\sim 30 \mu \mathrm{m}$. Рассеянный в обратном направлении свет при помощи зеркала и фокусирующей оптической системы направлялся на входную щель монохроматора. Проводилось пять измерений в разных местах на поверхности, полученные данные усреднялись.

Амплитуда электрического вектора света, падающего на поверхность поглощающего образца, затухает экспоненциально от поверхности вглубь. Эффективная толщина поверхностного слоя, о строении которого несет информацию спектр отражения, задана глубиной $h$, на которой амплитуда электрического вектора света уменьшается в $e \sim 2.7$ раз (e- основание натуральных логарифмов), а интенсивность света - в $e^{2} \sim 8$ раз. Она вычислена по формуле [10]

$$
h \approx \frac{1}{4 \pi v k_{e}},
$$

где $k_{e}-$ показатель поглощения.

Кристаллы кварца и полевого шпата в областях 285 и $514.5 \mathrm{~nm}$ практически не поглощают свет. Однако из-за высокой пористости образца свет сильно рассеивается. По этой причине точную величину эффективной толщины поверхностного слоя для случая, когда использовались методы PL и рамановской спектроскопии, оценить невозможно.

Влияние рассеяния на интенсивность IR-спектров меньше. Это позволило грубо оценить величину $h$. Оказалось, что $h$ в диапазоне волновых чисел $400-1200 \mathrm{~cm}^{-1}$ равна $\sim 1 \mu \mathrm{m}[5,6]$.

\section{3. Результаты измерений}

3.1. Результаты, полученные методом IR - с п е к р о с к о п и и. На рис. 1 приведены IR-спектры отражения поверхностей торца цилиндра (1), поверхности разрушения (2) и кристалла кварца (3) в области 850-1300 $\mathrm{cm}^{-1}$. В спектре кристалла кварца в этой области спектра наблюдаются два максимума: 1108 и $1177 \mathrm{~cm}^{-1}$. Они соответствуют валентным колебаниям кристаллической решетки $\alpha$-кварца $[11,12]$. В спектрах поверхностей торца и разрушения наблюдаются еще два максимума: 1086 и $1220 \mathrm{~cm}^{-1}$. Согласно [13,14], они появляются из-за рассеяния света на зернах кварца, линейный размер которых составляет несколько микрометров. Важно, что чем меньше размер зерен, тем больше интенсивность этих максимумов. Тогда из рис. 1 следует, что в поверхностном слое разрушения линейный размер зерен меньше, чем на торцах образца.

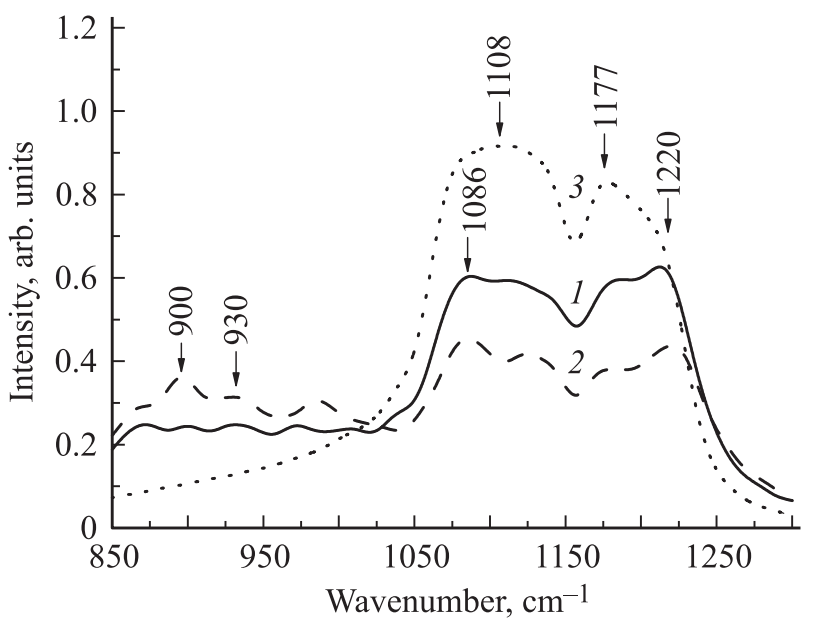

Рис. 1. Спектр отражения поверхностей торца цилиндра (1), поверхности разрушения (2) и кристалла кварца (3) в области $850-1300 \mathrm{~cm}^{-1}$

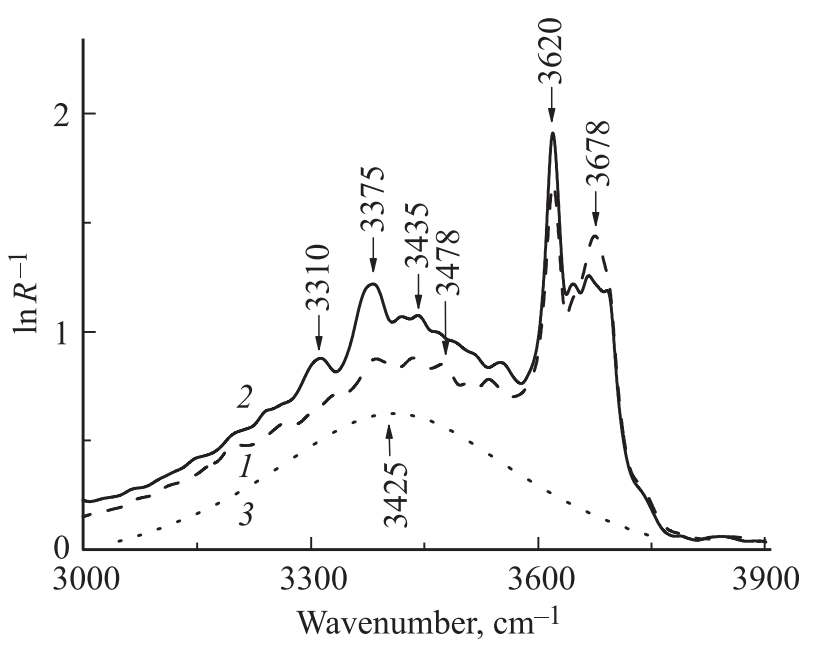

Pиc. 2. IR-спектры поглощения воды и растворенных в ней веществ на поверхности торца цилиндра (1) и поверхности разрушения (2). 3 - полоса поглощения воды, не содержащей примесей. 
Полосы $\sim 900$ и $930 \mathrm{~cm}^{-1}$ соответствуют колебаниям кристаллической решетки монтмориллонита и каолинита $[15,16]$. Эти породы цементируют кристаллы кварца и придают жесткость кварцевому песчанику. Из рис. 1 следует, что интенсивность этих полос увеличивается, т. е. концентрация цементирующих кристаллов в поверхностном разрушенном слое больше, чем на торцах образца.

Поверхности образца покрыты тонким слоем воды, содержащей ионизированные примеси. На рис. 2 приведены IR-спектры торца цилиндра и поверхности разрушения в области $3000-3900 \mathrm{~cm}^{-1}$ в координатах $\ln R^{-1}-v$, где $R-$ коэффициент отражения, а $v-$ волновое число. Интенсивность максимумов в таких спектрах пропорциональна концентрации поглощающих молекул. В спектре воды без примесей в этой области наблюдается широкая полоса $3425 \mathrm{~cm}^{-1}$. Она приписана молекулам воды, связанным друг с другом водородными связями [17]. Максимумы 3310, 3435 и $3478 \mathrm{~cm}^{-1}$ приписаны валентным колебаниям ОН в соединениях $\mathrm{AlOH}$ и $\mathrm{LiOH}$, а $3620 \mathrm{~cm}^{-1}$ - в парах группировок $\mathrm{SiOH}$ в поверхностном слое кварца $[18,19]$. В спектре поверхности разрушения интенсивность этих максимумов увеличивается. Это показывает, что концентрация группировок $\mathrm{AlOH}, \mathrm{LiOH}$ и $\mathrm{SiOH}$ на поверхности разрушения возрастает.

3.2. Результаты, полученные методом PL-cпектроскопии. На рис. 3 приведены спектры PL торца цилиндра и поверхности разрушения. В них наблюдается три полосы: 2.4, 2.7 и $3.2 \mathrm{eV}$. Полоса $2.4 \mathrm{eV}$ соответствует $\equiv \mathrm{Si}-\mathrm{O}^{-}$, отрицательный заряд кислорода скомпенсирован ионами $\mathrm{Li}^{+}, \mathrm{Na}^{+}$или $\mathrm{H}^{+}[18,19]$. Полоса $2.7 \mathrm{eV}$ приписана самозахваченному экситону [20], а полоса $3.2 \mathrm{eV}$ - отрицательно заряженному центру $\left[\mathrm{AlO}_{4}\right]^{-}[21]$. Из рис. 3 следует, что интенсивность полос 2.4 и $2.7 \mathrm{eV}$ в спектре поверхности разрушения меньше, чем в спектре торца цилиндра. Это означает, что на поверхности разрушения концентрация $\mathrm{Si}-\mathrm{O}^{-}$и экситонов уменьшается.

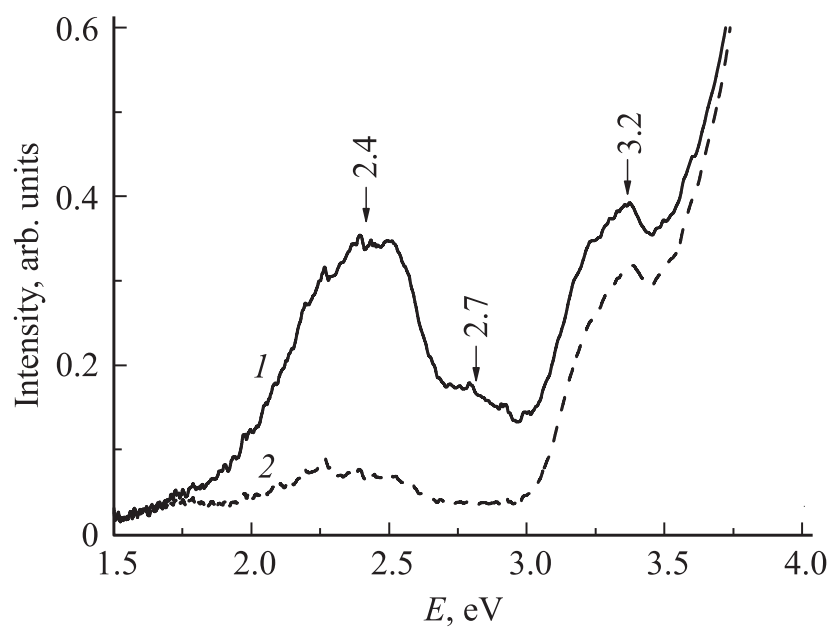

Pис. 3. PL-спектры поверхности торца цилиндра (1) и поверхности разрушения (2).

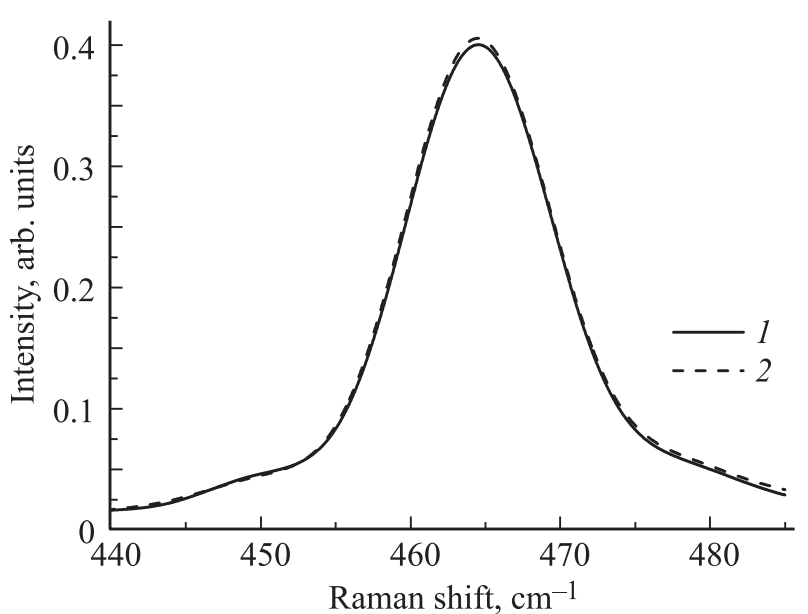

Рис. 4. Полоса $464 \mathrm{~cm}^{-1}$ в рамановских спектрах поверхностей торца (1) и разрушения (2).

3.3. Результаты, полученные методом рамановской спектроскопии. Исследование строения образцов горных пород после их размола в очагах землетрясений или после трения земных плит $[5,22,23]$ показало, что кристаллы кварца в них раздроблены до наноразмеров. Интересно было выяснить, дробятся ли до таких размеров зерна кристаллов кварца при разрушении образца. Чтобы ответить на этот вопрос, были исследованы форма и положение полосы $464 \mathrm{~cm}^{-1}$. В работах $[5,22,23]$ было установлено, что форма этой полосы в спектрах нанокристаллов становится асимметричной (увеличивается интенсивность в области длинноволнового крыла), а максимум полосы смещается в низкочастотную сторону. Однако, как следует из рассмотрения рис. 4 , в рамановских спектрах торца и поверхности разрушения кварцевого песчаника форма этой полосы симметричная. Это показывает, что размеры кристаллов кварца в поверхностных слоях торца и поверхности разрушения кварцевого песчаника больше $\sim 0.1 \mu \mathrm{m}$.

\section{4. Обсуждение результатов}

Как уже упоминалось, кварцевый песчаник содержит кристаллы кварца, цементированные монтмориллонитом и каолинитом. Разрушение образца вызвало высыпание порошка, фотография которого приведена на рис. 5, распределение частиц порошка по размерам представлена на рис. 6. Оказалось, что средний размер частиц порошка составляет $\sim 2 \mu \mathrm{m}$. Это прекрасно согласуется с приведенными выше данными IR-спектроскопии, согласно которым появление новых максимумов 1108 и $1177 \mathrm{~cm}^{-1}$ вызвано рассеянием света на частицах с линейными размерами в несколько микрометров.

Поверхности цилиндра и разрушения покрыты тонким слоем воды, молекулы которой связаны водородными связями между собой, с группировками $\mathrm{SiOH}$ и примесями $\mathrm{Al}$ и $\mathrm{Li}$, замещающими атомы кремния в кристаллической решетке кварца. Концентрация этих группировок и примесей в слое воды на поверхности разрушения выше, 


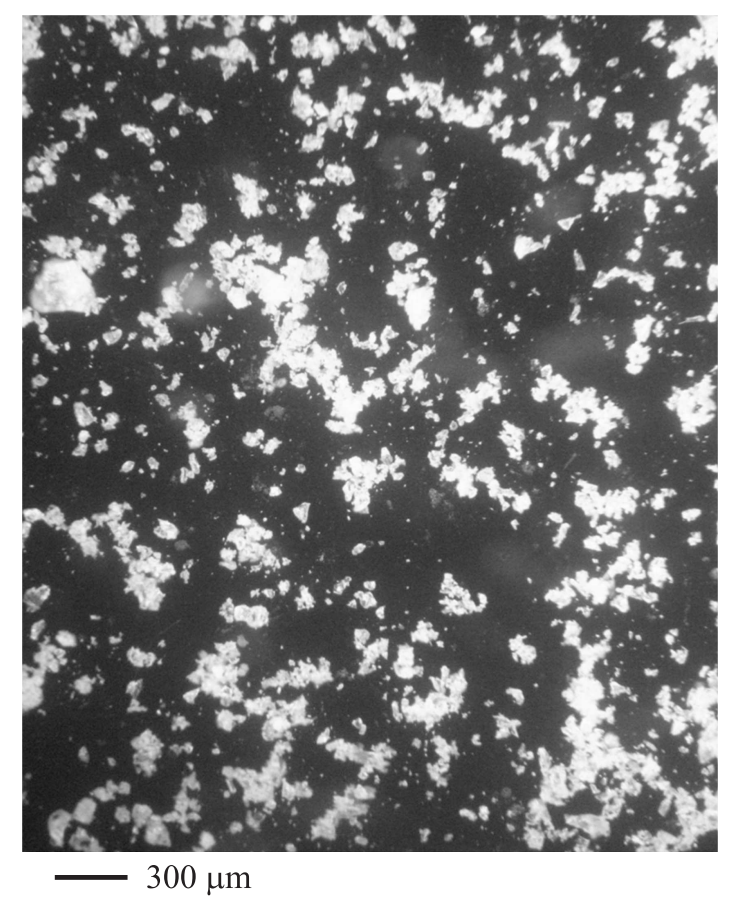

Рис. 5. Фотография частиц порошка, образовавшихся после разрушения песчаника.

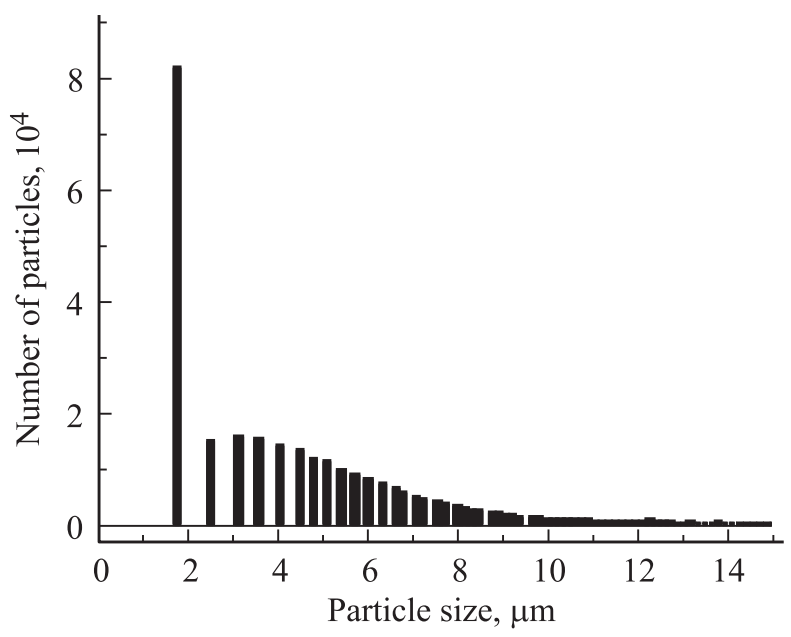

Рис. 6. Распределение по размерам частиц порошка, образовавшихся после разрушения песчаника.

чем на поверхности торца цилиндра. По-видимому, часть таких группировок и примесей выходит из поверхностного слоя кварцевого песчаника в воду. Вероятно, по этой же причине в воде растет и концентрация цементирующих веществ: монтмориллонита и каолинита.

Концентрация дефектов кристаллической решетки кварца - $\mathrm{Si}-\mathrm{O}^{-}$и самозахваченных экситонов в поверхностном слое разрушения, наоборот, меньше, чем в таком же слое торца цилиндра. Вероятно, это вызвано разрушением кристаллов кварца, содержащих такие дефекты. Действительно, кристаллическая решетка кварца около дефектов искажена, что должно вызывать понижение ее прочности.

\section{5. Заключение}

При раскалывании кварцевого песчаника разрушаются не только кристаллы низкопрочных цементирующих веществ, но прочные кристаллы кварца. Концентрация дефектов строения кристаллической решетки $\left(\mathrm{Si}-\mathrm{O}^{-}\right.$, самозахваченных экситонов и т.п.) в них понижена. Вероятно, дефекты уменьшают прочность зерен кварца, и при раскалывании они разрушаются в первую очередь.

\section{Список литературы}

[1] J.H. Dietrich. J. Geophys. Res. 77, 3690 (1972).

[2] C.H. Scholz. The mechanics of earthquakes and faulting. 2nd ed. Cambridge University Press, Cambridge, (2002). $471 \mathrm{p}$.

[3] G. Di Toro, R. Han, T. Hirose, N. De Paola, S. Nielsen, K. Mizoguchi, F. Ferri, M. Cocco, T. Shimamoto. Nature 471, 494 (2011).

[4] A. Niemeijer, G. Di Toro, W.A. Griffith, A. Bistacchi, S.A.F. Smith, S. Nielsen. J. Struct. Geology 39, 2 (2012).

[5] Г.А. Соболев, С.М. Киреенкова, Ю.А. Морозов, А.И. Смульская, В.И. Веттегрень, В.Б. Кулик, Р.И. Мамалимов. Физика Земли 9-10, 17 (2012).

[6] Г.А. Соболев, В.И. Веттегрень, В.В. Ружич, Л.А. Иванова, Р.И. Мамалимов, И.П. Щербаков. Вулканология и сейсмология 3, 3 (2015).

[7] Г.А. Соболев, В.И. Веттегрень, В.В. Ружич, С.М. Киреенкова, А.И. Смульская, Р.И. Мамалимов, В.Б. Кулик. Геофиз. исследования 17, 4, 5 (2015).

[8] В.И. Веттегрень, А.В. Пономарев, Г.А. Соболев, И.П. Щербаков, Р.И. Мамалимов, В.Б. Кулик, А.В. Патонин. ФТТ 59, 589 (2017)

[9] А.В. Патонин, А.В. Пономарев, В.Б. Смирнов. Сейсмические приборы 49, 1, 19 (2013).

[10] M. Born, E. Wolf. Principles of optics. 2nd ed. Pergamon Press, Oxford (1964). $856 \mathrm{p}$.

[11] W.G. Spitzer, D.A. Kleinman. Phys. Rev. 121, 1324 (1961).

[12] J. Etchepare, M. Merian, P.J. Kaplan. Chem. Phys. 60, 1873 (1974).

[13] J.W. Salisbury, A. Wald. Icarus 96, 121 (1992).

[14] J.R. Aronson, A.G. Emslie. Appl. Opt. 12, 2573 (1973).

[15] M.A. Karakassides, D. Gournis, D. Petridis. Clay Miner. 34, 429 (1999).

[16] L. Vaculíková, E. Plevová, S. Vallová, I. Koutník. Acta Geodyn. Geomater. 8, 1, 59 (2011).

[17] H. Yamagishi, S. Nakashima, Y. Ito. Phys. Chem. Miner. 24, 66 (1997).

[18] S. Suzuki, S. Nakashima. Phys. Chem. Miner. 26, 217 (1999).

[19] S. Lameiras, E.H.M. Nunes, W.L. Vasconcelos. Mater. Res. 12, 3, 315 (2009).

[20] B. Perny, P. Eberhardt, K. Ramseyer, J. Mullis. Am. Miner. 77, 534 (1992).

[21] J. Götze. Microsc. Microanal. 18, 1270 (2012).

[22] Г.А. Соболев, В.И. Веттегрень, С.М. Киреенкова, В.Б. Кулик, Ю.А. Морозов, А.И. Смульская. Физика Земли 6, 7 (2007).

[23] Г.А. Соболев, Ю.С. Геншафт, С.М. Киреенкова, Ю.А. Морозов, А.И. Смульская, В.И. Веттегрень, В.Б. Кулик. Физика Земли 6, 465 (2011). 